\title{
A Novel Strategy for Cervical Cancer Prevention Using Cervical-Vaginal Self-Collected Samples Shows High Acceptability in Women Living in Low-Income Conditions from Bucaramanga, Colombia
}

This article was published in the following Dove Press journal:

International Journal of Women's Health

Laura M Torrado-García Ruth A Martínez-Vega (D) Bladimiro Rincon-Orozco (D)

Microbiology School, Universidad Industrial De Santander, Bucaramanga, Santander, Colombia
Correspondence: Bladimiro Rincon-

\section{Orozco}

Email blrincon@uis.edu.co
Introduction: Human papillomavirus molecular detection prevents cervical cancer (CC). To widen its use, cervical-vaginal self-collection devices are proposed. Our aim was to determine the acceptability of self-sampled cervical-vaginal protocol and the reproducibility of results using HPV detection brushes in a low-income Colombian population between 35 and 65 years old.

Methods: Cross-sectional study including women classified as medium to high-risk for developing $\mathrm{CC}$ by using a short-standardized survey. After receiving instructions, women self-collected a cervical-vaginal sample. Subsequently, a perception survey was conducted. Results: Four hundred and twenty-three women performed self-collected sampling. The median age was 46.5 years (IQR 40-52), 56.5\% were housewives, and 55.1\% had finished elementary school. About $99 \%$ of the population $(n=419)$ considered that they understood the instructions, $19.4 \%(\mathrm{n}=82)$ reported having concerns about the self-collected sample, $9.2 \%$ $(n=39)$ distrusted the results because of the self-collection, $7.3 \%(n=31)$ felt uncomfortable with the procedure, and $9.7 \%(n=41)$ reported some pain. The majority would recommend the procedure to others $(99 \%), 88.5 \%$ of the sampled population preferred the self-collected method, $4 \%$ preferred conventional cytology, and 7.3\% were not sure. The reasons behind favoring the self-collected procedure included privacy $(n=149,40.1 \%)$, comfort $(n=110$, $29.7 \%)$, easiness $(n=52,14 \%)$, reliability $(n=46,12.4 \%)$, and less painful $(n=110,29.7 \%)$. The percentage of HPV detection agreement between the self-collected and the healthcare professional-collected procedures was 98.99\% (Cohen's Kappa=0.9774).

Conclusion: Women living in low-income households in Bucaramanga, Colombia preferred the self-sampling procedure because it was easy to use, convenient, and private, resulting in 98\% acceptability, and positioning it as an excellent tool for CC prevention.

Keywords: cervical smear, uterine cervical neoplasms, female, self-collected HPV

\section{Introduction}

Cervical cancer (CC) is the fourth most common female cancer, and it is estimated that 500,000 new cases occur annually worldwide with approximately 50\% mortality. ${ }^{1}$ Developing countries account for $70 \%$ of these deaths. Colombia reported since 2018, an annual CC rate of 18.2 cases per 100,000 women, positioning Colombia with one of the highest incidence rates in Latin America. ${ }^{2}$

Conventional cytology is currently the screening test used for the prevention of $\mathrm{CC}$ in Colombia. A low coverage, few follow-ups of screened women, and poor 
sensitivity of this technique are part of the pitfalls of the Colombian National Prevention Program. ${ }^{3,4}$ Moreover, women do not comply with annual cytology appointments because of shame, pain, and fear. ${ }^{5}$ According to the National Demography and Health Survey, 43.4\% of Colombian women who have had cytology at some time in their lives reported fear as the main reason for abandoning the program, and $25.8 \%$ do not have healthcare insurance. $^{6}$

Recently, the use of molecular tests, which detect human papillomavirus (HPV) DNA, has demonstrated beneficial results. ${ }^{7}$ These molecular tests and selfcollected protocols have been implemented to reduce the issues associated with conventional cytology in some countries. The self-collected protocol consists of women taking a sample of their cervix with a disposable sterilized device (brush); this procedure has good concordance and accuracy to detect HPV DNA when it is compared to samples collected by a qualified healthcare professional. ${ }^{8,9}$

Nation-wide implementation of the self-collected protocol could positively impact the participation of women in CC prevention programs, especially in low and middleincome countries. Particularly in Colombia, our study was the first to report the use of a self-collected protocol. Therefore, this work aimed to determine the acceptability of the cervical-vaginal self-collected samples and the reproducibility of results in adult women with lowincome settings living in Bucaramanga, Colombia.

\section{Materials and Methods Design and Study Population}

A cross-sectional study was conducted in women between 35 and 65 years old living in the northern part of Bucaramanga, Colombia. These women reported having had sexual activity during their life. Pregnant women and women with hysterectomy were excluded. Bucaramanga is the capital of the state of Santander. The city has 528,610 inhabitants, of which 273,905 are women according to the National Administrative Department of Statistics in 2018. The northern area of Bucaramanga is characterized as a low socioeconomic area according to the classification made by the government. This classification took into account the physical characteristics of the houses and the social environment where they are located (strata from 1 to 3 on a scale of 1 to 6 , where 1 is the lowest and 6 the highest). ${ }^{10}$

\section{Data and Sample Collection}

Convenience sampling was done from September 2016 to March 2018 using three mechanisms of recruitment: a) women who attended non-gynecological clinical assessments in different first-level care health centers; b) women who were visited at home; and c) women who were summoned by community leaders. These recruitment methods were used because it is not easy to encourage self-care in a low-educated population.

Women who agreed to participate filled out a short survey adapted from the Siteman Cancer Center, which classifies the risk of developing $\mathrm{CC}$ by assessing sexual and reproductive behaviors. According to these responses, participants were classified as women with low, moderate, and high risk to develop CC. ${ }^{11}$ Those women with moderate and high risk received visual and verbal instructions, to perform the cervical-vaginal self-collected sampling using a disposable sterilized brush.

After the self-collected sampling, participants answered a survey about the acceptability of the protocol for HPV screening. The survey consisted of 10 questions to determine the experience, comfort, and safety of the procedure. Besides, participants were asked their preference between this method and conventional cytology, and the reasons why they had chosen one over the other. ${ }^{12-14}$

\section{Reproducibility of the Self-Collected Sample Results} In 99 women, a double cyto-cervical sample was performed. One sample was taken by a trained health professional, while the other was self-collected by the participant. The order of the sample taken by a health professional or self-collected was made by simple randomization. The percentage agreement to detect HPV DNA and Cohen's Kappa was calculated.

\section{HPV Detection and Genotyping Using HPV Direct Flow CHIP}

HPV genotyping was performed by multiple PCR of the L1 gene codifying for a major viral capsid protein with the GP5 +/GP6 + primer sets, which detect the HPV-LR genotypes $-6,-11,-40,-42,-43,-44,-54,-55,-61$, $-62,-67,-69,-70,-71,-72,-81,-84$ and -89 and HPV-HR $-16,-18,-26,-31,-33,-35,-39,-45,-51$, $-52,-53,-56,-58,-59,-66,-68,-73$ and -82 , followed by specific hybridization in a matrix and enzymatic colorimetric detection (HPV Direct Flow CHIP, Master Diagnóstica, Spain). 
The samples were briefly resuspended in $3 \mathrm{~mL}$ cell preservation fluid (0.5 M EDTA, pH:8, acetic acid 0.1\%, methanol $50 \%$ ) and DNA was extracted from cervical samples by salting out. ${ }^{15}$ To perform PCR, $500 \mathrm{ng}$ of DNA was used following the manufacturer's instructions (Master Diagnóstica, Spain). The amplification cycles were as follows: 1 cycle $10 \mathrm{~min}$ at $25{ }^{\circ} \mathrm{C}$; 1 cycle at $94{ }^{\circ} \mathrm{C}$ for $3 \mathrm{~min} ; 15$ cycles of denaturation at $94{ }^{\circ} \mathrm{C} 30 \mathrm{~s}$, alignment $42{ }^{\circ} \mathrm{C} 30$ s and elongation $72{ }^{\circ} \mathrm{C} 30$ s; 35 cycles of denaturation at $94{ }^{\circ} \mathrm{C} 30$ s, alignment $60{ }^{\circ} \mathrm{C}$, elongation $72{ }^{\circ} \mathrm{C} 30 \mathrm{~s}, 1$ cycle at $72{ }^{\circ} \mathrm{C}$ for $5 \mathrm{~min}$ and finally $5 \mathrm{~min}$ $8^{\circ} \mathrm{C}$. Hybridization was performed in CHIP HPV membranes containing specific probes for HPV-High Risk (HR) and HPV-Low Risk (LR) genotypes. ${ }^{16}$

\section{Statistical Analysis}

Sociodemographic characteristics were described using absolute and relative frequencies for qualitative variables. For age and body mass index (BMI) variables, the median and interquartile range (IQR) were used because they had no normal distribution. Also, BMI was categorized according to the WHO definition as normal (BMI greater than 18.5 but less than 25), overweight (BMI equal to or greater than 25), obese (BMI equal to or greater than 30) and underweight (BMI less than 18.5). The prevalence of HPV infection was calculated with confidence intervals of $95 \%$ (CI95\%) using Wilson's method. The analysis was performed with the statistical software Stata SE 15.

\section{Ethical Considerations}

This work was approved by the ethics committee of the Bucaramanga Health Institute (ISABU), Colombia, and conducted following the Declaration of Helsinki (approval number 2000-39-01). Before participating in the study, women gave written informed consent.

\section{Results}

Out of the 828 women surveyed during the sampling period, 403 were excluded from the study because they had a low risk to develop CC according to results of the short survey adapted from the Siteman Cancer Center. Also, 2 women with moderate risk to develop $\mathrm{CC}$ were excluded because they refused to take the sample. A total of 423 women participated in the study who had a moderate to high risk to develop CC. These participants collected their samples following the self-collection protocol. The median age was 46.5 years; approximately $50 \%$ finished elementary school, lived in consensual union, and were housewives; and $89.5 \%$ had health insurance subsidized by the government. The majority of women lived in neighborhoods belonging to the lowest socioeconomic stratum. Regarding the availability of utilities, the majority of the studied population lived in houses with drinking water, electricity, and gas. However, only $36.4 \%$ had internet and 32.4\% landlines (Table 1).

Regarding risk factors for developing $\mathrm{CC}$, it was found that the majority of women have never smoked, $28.5 \%$ quit it, and only $10.2 \%$ currently smoke. Additionally, the majority of participants have had more than three sexual partners in their lifetime, $26.6 \%$ have had a sexually transmitted disease (STDs) at some point in their lives, and most women had conventional cytology in the last three years. Finally, it was found that the BMI of the majority of the women was greater than 25 , so they can be classified as overweight or obese (Table 1).

In assessing the acceptability of the self-collected sampling, most women said they adequately understood how to perform the procedure after giving the instructions. Furthermore, most women had no concern about their ability to practice the self-collected sampling and they did not distrust the results just because they had collected the sample themselves. Also, most women reported they did not find the procedure uncomfortable or painful, and $99 \%$ of all surveyed women said that they would recommend this screening procedure to prevent $\mathrm{CC}$ to a friend or a relative (Figure 1).

In general, the self-collected procedure had a good acceptance rate, $89 \%(n=372)$ of women stated that they preferred the self-collected sampling, $4 \%(n=17)$ preferred the conventional cytology, and $7.3 \%(n=31)$ had no preference. There are multiple reasons why the self-collected sampling was preferred to the conventional cytology. Among them, the most frequent was privacy $(\mathrm{n}=149)$, followed by comfortability ( $\mathrm{n}=52)$, easier to use $(\mathrm{n}=52)$, less painful $(\mathrm{n}=46)$, and reliability $(\mathrm{n}=46)$ (Figure 2).

It was possible to determine HPV infection in 422 out of the 423 participants, because 1 sample had a lot of blood, and was not possible to process it, and the woman refused to take a second sample. 180 of women were infected by at least one genotype of HPV resulting in a prevalence of HPV infection of $42.7 \%$ (CI95\% 38-47.4). The prevalence of HPV HR infection was $21.3 \%$ (CI95\% $17.7-25.5$ ) and of HPV BR was $17.3 \%$ (CI95\% 14-21.2). However, in $21.6 \%(n=39)$ of the infected women, it was not possible to determine the HPV genotype. The coinfection between HPV LR and 
Table I Sociodemographic Characteristics and Background of the Women Evaluated

\begin{tabular}{|c|c|}
\hline Characteristics & Measure \\
\hline Age Median (IQR) & $46.5(40-52)$ \\
\hline Years of studies completed & $6.3(4-9)$ \\
\hline Education level & $n=419$ \\
\hline Primary n (\%) & $231(55.1)$ \\
\hline High school & $144(34.4)$ \\
\hline No scholar education & $24(5.7)$ \\
\hline Technical & $15(3.5)$ \\
\hline Professional & $5(1.1)$ \\
\hline Civil status & $n=419$ \\
\hline Consensual Union & $203(48.4)$ \\
\hline Single & $88(21.0)$ \\
\hline Married & $78(18.6)$ \\
\hline Separated/Divorced & $32(7.6)$ \\
\hline Widow & $18(4.3)$ \\
\hline Occupation & $n=419$ \\
\hline Housewife & $237(56.5)$ \\
\hline Independent & $123(29.4)$ \\
\hline Employees & $48(11.4)$ \\
\hline Unemployed & $7(1.67)$ \\
\hline Students & $2(0.48)$ \\
\hline Retired & $2(0.48)$ \\
\hline Health care insurance & $n=412$ \\
\hline Subsidized by the government & $369(89.5)$ \\
\hline Contributory & $42(10.1)$ \\
\hline Special & $\mathrm{I}(0.2)$ \\
\hline Housing strata & $n=419$ \\
\hline Unrated & $4(0.9)$ \\
\hline Stratum one & $296(70.6)$ \\
\hline Stratum two & III (26.4) \\
\hline Stratum three & $8(1.9)$ \\
\hline Public utilities and others & $n=422$ \\
\hline Water & $419(99.2)$ \\
\hline Electricity & $416(98.5)$ \\
\hline Natural gas & $344(81.5)$ \\
\hline TV & $394(93.3)$ \\
\hline Fridge & $366(86.7)$ \\
\hline Washing machine & $260(61.6)$ \\
\hline Telephony & $154(36.4)$ \\
\hline Internet & $137(32.4)$ \\
\hline Smoking & $n=420$ \\
\hline Yes & $43(10.2)$ \\
\hline Used to smoke, but I left it & $120(28.5)$ \\
\hline Never smoked & $257(6 \mathrm{I} .1)$ \\
\hline Number of sexual partners & $n=420$ \\
\hline I partner & $25(5.9)$ \\
\hline 2 partners & $36(8.5)$ \\
\hline 3 or more partners & $359(85.4)$ \\
\hline
\end{tabular}

(Continued)
Table I (Continued).

\begin{tabular}{|l|l|}
\hline Characteristics & Measure \\
\hline Sexually transmitted infections & $\mathrm{n}=420$ \\
No & $30 \mathrm{I}(71.6)$ \\
Yes & $112(26.6)$ \\
Unknown & $7(1.67)$ \\
\hline Cytology in the last 3 years & $\mathrm{n}=420$ \\
No & $108(25.7)$ \\
Yes & $310(73.8)$ \\
Unknown & $2(0.4)$ \\
\hline Body mass index (BMI) & $\mathrm{n}=399$ \\
Median (IQR) & $27.1(25-33)$ \\
\hline Categorical BMI & $\mathrm{n}=399$ \\
Underweight & $3(0.50)$ \\
Normal & $103(25.8)$ \\
Overweight & $159(39.8)$ \\
Obese & $135(33.8)$ \\
\hline
\end{tabular}

HPV HR was determined by $5.2 \%(n=22)$ of women. Out of the $34 \mathrm{HPV}$ genotypes that the test can detect only 3 were not detected (HPV-11, HPV-89, and HPV-26). The most frequent HPV LR genotype was HPV-62/81 followed by HPV-71, and the most frequent HPV LR genotype was HPV-52 followed by HPV-31 (Figure 3A and B).

Regarding the evaluation of the reproducibility to detect HPV DNA between the self-collected sampling and the sample taken by trained health personnel, $52.5 \%$ of the women

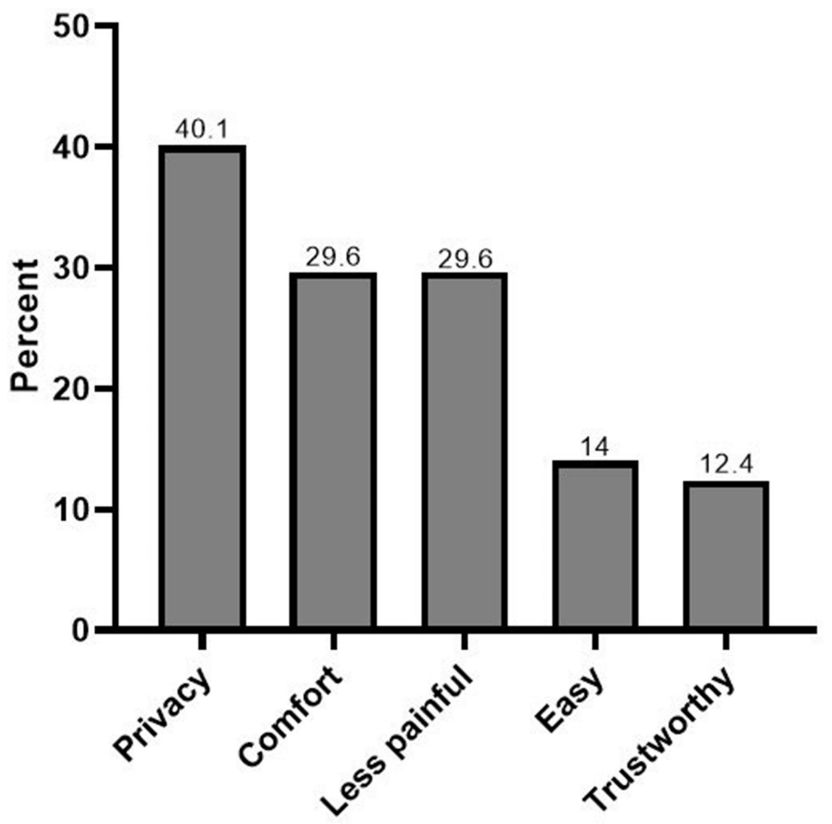

Figure I Perception of the self-collection of cervical-vaginal samples. 


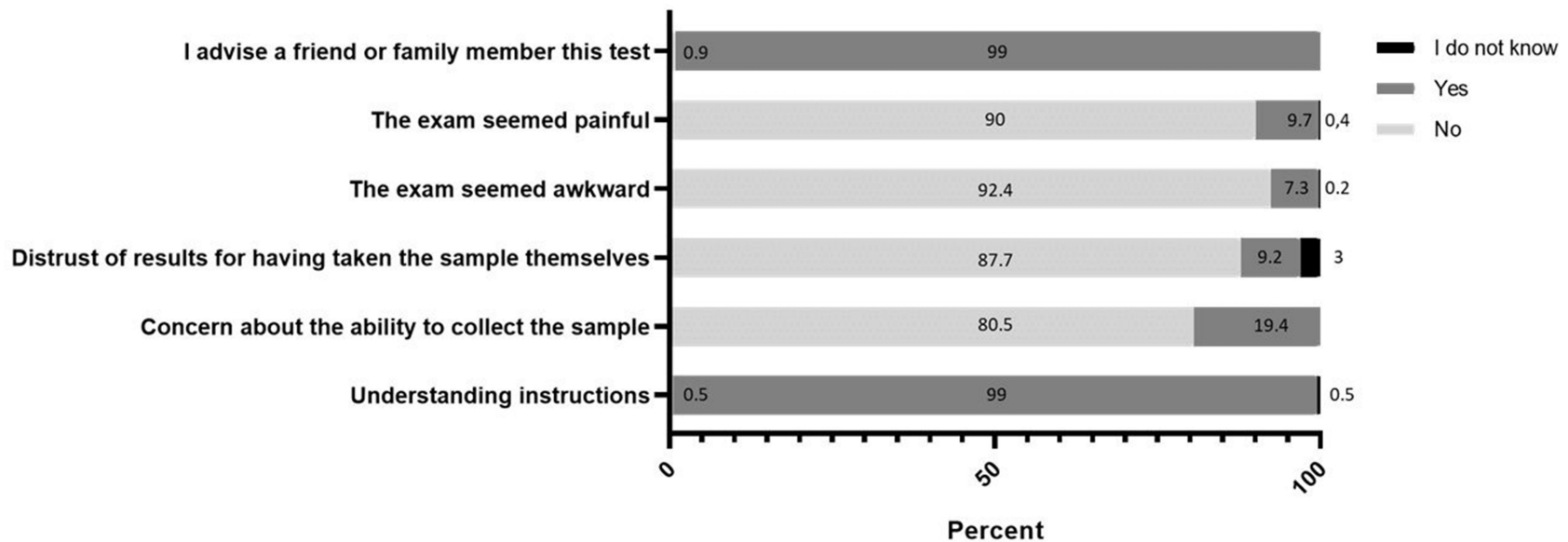

Figure 2 Reasons why participants preferred cervical-vaginal self-collected sampling.
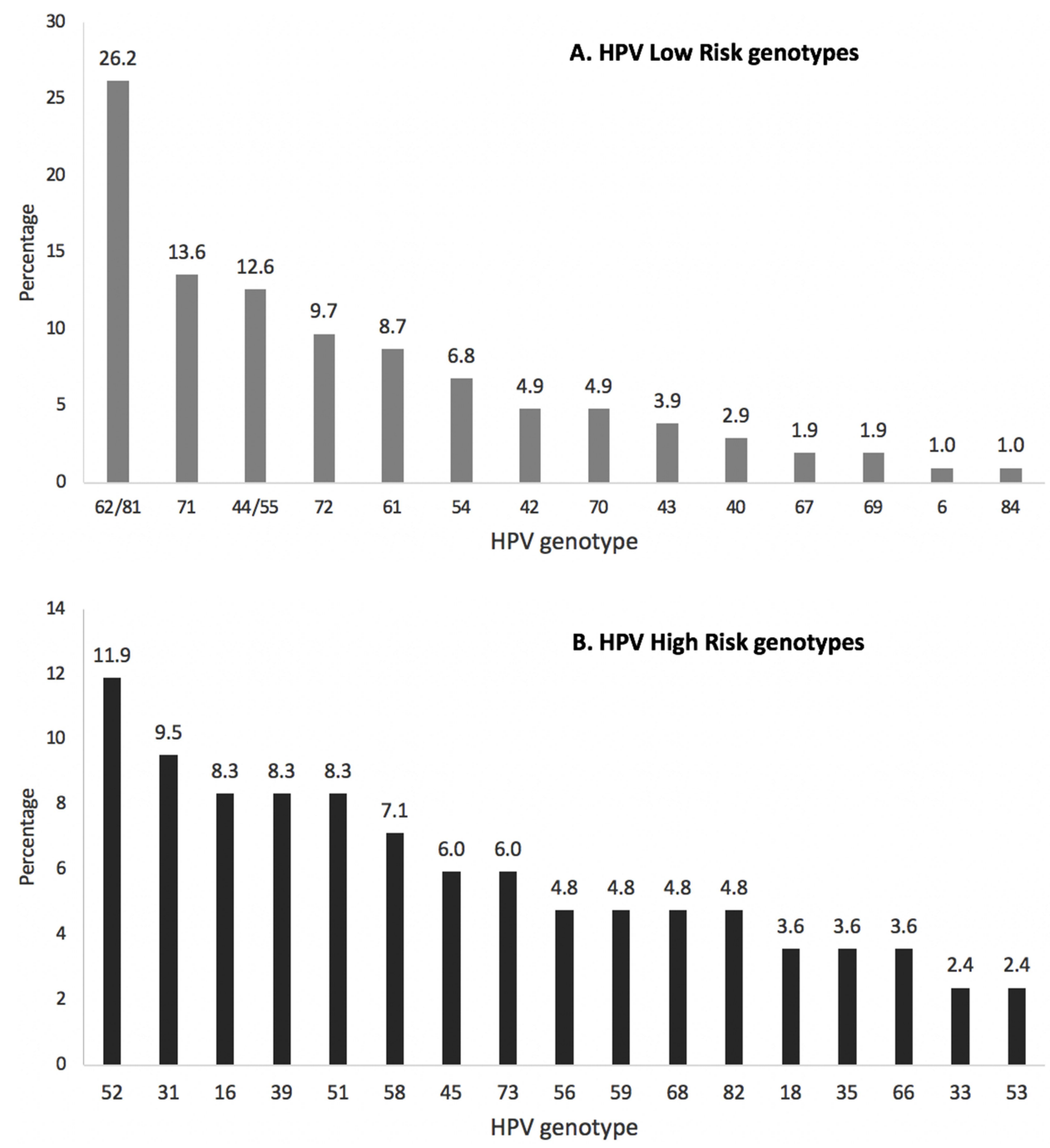

Figure 3 Frequency of HPV LR and HPV HR genotypes detected in sampled women.(A) HPV LR genotypes. (B) HPV HR genotypes. 
$(\mathrm{n}=52 / 99)$ randomly performed the self-collected sampling first. The percentage agreement to HPV detection was 98.99\% (Cohen's Kappa = 0.9774). Only one disagreement occurred; the self-collected sample gave a positive result, while the sample taken by the professional personnel gave a negative result. Among the positive results reported by both methods $(\mathrm{n}=33)$, there was a genotyping agreement in $96.97 \%$ of cases. There was only a disagreement with one sample, HPV HR-52, -45, -66, and HPV LR-71 was detected in the self-collected sample, while the sample is taken by the professional personnel only detected HPV HR- 52 .

\section{Discussion}

This study is the first conducted in Colombia about the implementation and acceptance of the cervical-vaginal self-collected protocol for HPV detection and CC prevention. It included women in vulnerable conditions who live in economically depressed areas in Bucaramanga, Colombia. Besides, the majority of these women have not achieved a high educational level and have health insurance subsidized by the government.

Fulfillment of the annual conventional cytology program has not been successful in Latin American countries and other parts of the world. For example, in France, it has been mentioned that conventional cytology has low coverage rates in the female population due to the cultural resistance of having a gynecological examination. ${ }^{17}$ In Colombia, there are statistically significant differences in access to the conventional cytology program depending on socioeconomic conditions. ${ }^{18-20}$ According to the 2010 national demography and health survey, $43.4 \%$ of women who have practiced conventional cytology reported fear as the main reason for abandoning the $\mathrm{CC}$ prevention program. Therefore, it is important to provide new CC prevention tools such as the cervicalvaginal self-collected sampling to diagnose HPV infection by molecular methodologies, which will help to eliminate barriers and improve $\mathrm{CC}$ prevention program nation-wide.

In this regard, self-collected sampling has been proposed as an effective alternative tool for women who have no interest in the prevention program or where there are socioeconomic barriers to perform conventional cytology. These limitations are well-known causes of the highest CC rates in some regions of the world. ${ }^{21,22}$

Concerning the training in the self-collected procedure, in this study, various teaching strategies were used, such as audiovisual material and in-person training by a health professional, as well as the option of taking a sample device to familiarize with it before collecting the sample. All of these strategies allowed most women to understand the instructions and coach them to collect the cervicalvaginal sample by themselves.

There were different perceptions about self-collected sampling; the majority of women considered this procedure comfortable or painless and they were not concerned about their ability to collect the sample. These findings were similar to a study done on 333 South African women infected with HIV. These women had an average age of 44 years and also received instructions on the self-collected sampling to detect HPV. In this study, $76.3 \%$ of women said that the collection was easy, and $77.9 \%$ reported that the procedure was very comfortable. ${ }^{23}$ Similarly, in New York a survey was conducted among 172 Hispanic women after they underwent gynecological examination and self-collection sampling at the same time; $69 \%$ reported ease of use, $62 \%$ felt less pain, $56 \%$ agreed they could do it alone, and 52\% liked the privacy. These showed that self-collected sampling can remove many barriers in different cultures and populations. ${ }^{24}$

The findings regarding the acceptability of the selfcollected sampling and its preference over the conventional cytology are compelling in our study. In general, women reported they would recommend the procedure to friends or relatives. This correlates with the majority of participants who prefer this method over the cytology for greater intimacy, comfort, less pain, and greater ease, among other reasons. Similarly, a study that included 1069 Mexican women with similar sociodemographic characteristics to our population reported $71 \%$ of women preferred the selfcollected sampling because it was more comfortable. ${ }^{25}$ Furthermore, a study conducted with 19,340 women from India, Nicaragua, and Uganda found that they preferred the self-collected sampling $(p<0.001)$ in comparison to samples taken by professionals using speculum. ${ }^{26}$

However, our results differ with those of a cohort of women from Puerto Rico, where 67\% reported that despite feeling less discomfort with the self-collected sampling, they preferred the sampling done by a gynecologist because of confidence. ${ }^{14}$ In our study, only $19 \%$ were concerned about their ability to take the sample by themselves, and $9 \%$ were distrustful of the results. On the contrary, $12.4 \%$ who preferred the self-collected sampling did so because they considered it to be more reliable.

Moreover, a multicenter study with women from India, Uganda, and Nicaragua by Pooja et al 2014, showed that over $78 \%$ of them considered self-collected sampling easy. ${ }^{26}$ This differs from our results because only $14 \%$ of the population studied in Bucaramanga reported this reason. This could be explained because the women of the present study prioritized 
intimacy as the most important reason to prefer self-collected sampling (40\%), followed by comfort (30\%) (Figure 2). Furthermore, our study reported a percentage agreement of 98.99\% (Cohen's Kappa= 0.9774) between the self-collected sampling and the one done by healthcare professionals. This shows that self-collected sampling is a useful tool in screening coverage for women who report fear and pain during sampling done by healthcare professionals.

Our research presented some limitations. One of them was the inclusion of women only from low socioeconomic stratums because in Colombia this population is the most affected by CC. However, it could be expected that the acceptability of the self-collected sampling increases if women with higher socio-economic settings are onboard with it. Another limitation was the non-inclusion of women from rural areas. Therefore, it would be useful to carry out a future study to evaluate the acceptability of self-collected sampling in this population where illiteracy and vulnerability are higher than women from urban areas. In conclusion, this study is the first in Colombia that reports the acceptability of the self-collected sampling for the detection of HPV infection and the reproducibility of results. Besides, taking into account the preference of the cervical-vaginal self-collected sampling over the conventional cytology reported by the participating women and the high reproducibility, it suggests this is an excellent tool for $\mathrm{CC}$ prevention.

The use of this new tool is proposed within the screening program, which would have a positive impact on the $\mathrm{CC}$ prevention because the self-collected sampling could improve adherence and follow-up to the national program "Comprehensive Route of Care for Cervical Cancer" which includes screening with molecular tests for HPV infection.

\section{Acknowledgments}

This project was supported by grant 110272553474MinCiencias-Colombia and Universidad Industrial de Santander, Colombia.

\section{Disclosure}

Ruth Martínez-Vega reports grants from MinCienciasColombia, during the conduct of the study. The authors declare that they have no other potential conflicts of interest.

\section{References}

1. Bray F, Ferlay J, Soerjomataram I, Siegel R, Torre L, Jemal A. "Global cancer statistics 2018: GLOBOCAN estimates of incidence and mortality worldwide for 36 cancers in 185 countries,". CA Cancer J Clin. 2018;68:394-424. doi:10.3322/caac.21492
2. Soto-de Leon S, et al. "Distribution patterns of infection with multiple types of human papillomaviruses and their association with risk factors,". PLoS One. 2011;6(2):e14705. doi:10.1371/journal.pone.001 4705

3. Cendales R, Wiesner C, Murillo RH, Piñeros M, Tovar S, Mejía JC. "La calidad de las citologías para tamización de cáncer de cuello uterino en cuatro departamentos de Colombia: un estudio de concordancia,”. Biomédica. 2010;30(1):107. doi:10.7705/biomedica.v30i1. 158

4. Murillo R, Luna J, Gamboa O, Osorio E, Bonilla J, Cendales R. "Cervical cancer screening with naked-eye visual inspection in Colombia,”. Int J Gynecol Obstet. 2010;109(3):230-234. doi:10.10 16/j.ijgo.2010.01.019

5. Logan L, Mcllfatrick S. "Exploring women's knowledge, experiences and perceptions of cervical cancer screening in an area of social deprivation,”. Eur J Cancer Care. 2011;20(6):720-727. doi:10.11 11/j.1365-2354.2011.01254.x

6. Profamilia. "Encuesta Nacional de Demografía y Salud 2010,”. 2011.

7. Sankaranarayanan R, et al. "HPV screening for cervical cancer in rural India,”. N Engl J Med. 2009;360(14):1385-1394. doi:10.1056/ NEJMoa0808516

8. Arbyn M, et al. "Accuracy of human papillomavirus testing on selfcollected versus clinician-collected samples: A meta-analysis,". Lancet Oncol. 2014;15(2):172-183. doi:10.1016/S1470-2045(13) 70570-9

9. Arbyn M, Castle PE. "Offering self-sampling kits for HPV testing to reach women who do not attend in the regular cervical cancer screening program,". Cancer Epidemiol Biomarkers Prev. 2015;24 (5):769-772. doi:10.1158/1055-9965.EPI-14-1417

10. Departamento Administrativo Nacional de Estadística, "Censo Nacional de Población y Vivienda - DANE-DCD-CNPV. 2018:1-27.

11. Colditz GA. Siteman Cancer Center. SAGE Encyclopedia Cancer Society. 2015.

12. Kahn JA, et al. "Acceptability of human papillomavirus self testing in female adolescents,". Sex Transm Infect. 2005;81(5):408-414. doi:10.1136/sti.2004.012047

13. Broquet C, Triboullier D, Untiet S, Schafer S, Petignat P, Vassilakos P. "Acceptability of self-collected vaginal samples for HPV testing in an urban and rural population of Madagascar,". Afr Health Sci. 2015;15(3):755-761. doi:10.4314/ahs.v15i3.8

14. Ortiz AP, et al. "Acceptability of cervical and anal hpv self-sampling in a sample of hispanic women in Puerto Rico,". P R Health Sci J. 2012;31(4):205-212.

15. Miller SA, et al. "A simple salting out procedure for extracting DNA from human nucleated cells.”. Nucleic Acids Res. 1988;16(3):1215. doi:10.1093/nar/16.3.1215.

16. Torrado LM, et al. "Genotipificación del Virus de Papiloma Humano en mujeres de la comuna norte de Bucaramanga,". Rev La Univ Ind Santander Salud. 2018;50(3):225-232.

17. Jacquème $\mathrm{B}$, Coudert $\mathrm{C}$, Mabriez JC, Bonnier $\mathrm{P}$, Piana L. "Antécédents de dépistage cytologique chez les patientes traitées pour cancer infiltrant du col de l'utérus,". Bull Cancer. 2002;89 (2):234-240.

18. Castro-Jiménez MA, Londoño-Cuellar PA, Vera-Cala LM. "Asistencia a citología del cuello uterino y sus determinantes en una población rural Colombiana, 1998-1999,". Rev Salud Publica. 2006;8(3):248-257. doi:10.1590/S0124-00642006000300010

19. Lucumí Cuesta DI, Gómez Gutiérrez LF. “Accesibilidad a los servicios de salud en la práctica de citología reciente de cuello uterino en una zona urbana de Colombia,". Rev Esp Salud Publica. 2004;78 (3):367-377. doi:10.1590/S1135-57272004000300006

20. Calderón CAA, Botero JC, Bolaños JO, Martínez RR. "[The Colombian healthcare system: 20 years of achievements and problems].,". Cien Saude Colet. 2011;16(6):2817-2828. doi:10.1590/ S1413-81232011000600020 
21. Sultana F, et al. "Rationale and design of the iPap trial: A randomized controlled trial of home-based HPV self-sampling for improving participation in cervical screening by never- and under-screened women in Australia,". BMC Cancer. 2014;14(1). doi:10.1186/14712407-14-207.

22. Madzima TR, Vahabi M, Lofters A. "Emerging role of HPV selfsampling in cervical cancer screening for hard-To-reach women,". Canadian Family Physician. 2017;63(8):597-601.

23. Stuart A, Obiri-Yeboah D, Adu-Sarkodie Y, Hayfron-Benjamin A, Akorsu AD, Mayaud P. "Knowledge and experience of a cohort of HIV-positive and HIV-negative Ghanaian women after undergoing human papillomavirus and cervical cancer screening,". BMC Womens Health. 2019;19:1. doi:10.1186/s12905-019-0 818-y
24. Anhang R, Nelson JA, Telerant R, Chiasson MA, Wright TC. "Acceptability of self-collection of specimens for HPV DNA testing in an urban population,". J Women's Heal. 2005;14(8):721-728. doi:10.1089/jwh.2005.14.721

25. Dzuba IG, et al. "The acceptability of self-collected samples for HPV testing vs. The pap test as alternatives in cervical cancer screening,". $J$ Women's Heal Gender-Based Med. 2002;11(3):265-275. doi:10. 1089/152460902753668466

26. Bansil P, Wittet S, Lim JL, Winkler JL, Paul P, Jeronimo J. "Acceptability of self-collection sampling for HPV-DNA testing in low-resource settings: a mixed methods approach,". BMC Public Health. 2014;14:596. doi:10.1186/1471-2458-14-596

\section{Publish your work in this journal}

The International Journal of Women's Health is an international, peerreviewed open-access journal publishing original research, reports, editorials, reviews and commentaries on all aspects of women's healthcare including gynecology, obstetrics, and breast cancer. The manuscript management system is completely online and includes a very quick and fair peer-review system, which is all easy to use. Visit http://www.dovepress.com/testimonials.php to read real quotes from published authors. 